\title{
EVALUATION OF ACOUSTICAL PARAMETERS OF AQUEOUS SOLUTION OF SODIUM CHLORIDE AND POTASSIUM CHLORIDE USING ULTRASONIC WAVES
}

\author{
S. Sasikumar ${ }^{1}$, G. Meenakshi ${ }^{2}$ \\ ${ }^{1}$ Research scholar in Karpagam University Coimbatore \\ ${ }^{2}$ Associate Professor of Physics in K.M.C.P.G.S (Retired), Government of Pondicherry, Pondicherry.
}

\begin{abstract}
The study of behaviour of propagation of ultrasonic waves in liquid system and solids is now rather well established as an effective means for examining certain physical properties of the materials. It is particularly well adapted to examine changes in such physical properties while they occur. The data obtained from ultrasonic propagation parameters such as ultrasonic velocity, adiabatic compressibility, molar volume, free length etc; and their variation with concentration of one of the component of the medium are useful in understanding the nature of molecular interaction in terms of physical parameters owing to the sensitivity to very low population densities at high energy states ultrasonic methods have been preferred and are reported to be complementary to other techniques like dielectric relaxation, I.R spectroscopy, N.M.R etc. Hence the author preferred to study the ultrasonic velocity and density measurement of aqueous solutions for $\mathrm{NaCl}$ and $\mathrm{KCl}$ of various concentrations. One of the important intermolecular properties of a liquid is the free length $L_{f}$ between the surfaces of two neighbouring molecules and in the distance covered by the propagating acoustic waves between the surfaces of the two neighbouring molecules. The non-linear variations are observed in acoustic parameters of $\mathrm{NaCl}$ and $\mathrm{KCl}$ solutions indicating the formation of complex ions. Molecular interactions can be studied through Rao's constants and Wada's constants which are constants in non interacting systems. The abrupt change observed in Rao's constant and Wada's constant shows existence of molecular interaction.
\end{abstract}

Keywords: Molecular interaction, Intermolecular length, Rao 's constant (R), Wada's constant (B)

\section{INTRODUCTION}

The ultrasonic studies provide a wealth of information about the state of liquids. It explains many properties of liquids and solutions. The measurement of ultrasonic velocity in pure liquids and mixtures is an important tool to study the physicochemical properties and also explains the nature of molecular interactions. The parameters obtained in such a study are used in turn to derive an insight into the molecular interaction in such systems. Molecular properties in liquid state are very useful in chemical analysis, thermodynamic and physical properties. A number of researcher's ${ }^{[1-11]}$ has investigated the molecular interaction in binary and ternary mixtures. In the present paper we have computed $\mathrm{R}-$ Rao's number, C - Ultrasonic velocity, B - Wada's constant, $\rho-$ Density of the solution, $\mathrm{L}_{\mathrm{f}}$ - Free length, $\beta \mathrm{s}$ - Adiabatic compressibility, RA - Relative association, $\mathrm{h}$ - hydration number of pure liquids and it's mixtures at $2 \mathrm{MHz}$ frequency at a temperature of $303 \mathrm{~K}$.

\section{EXPERIMENTAL DETAILS}

The Ultrasonic speed in pure liquids and their binary mixtures were measured using a single crystal variable-path interferometer at $2 \mathrm{MHz}$ with an accuracy of $\pm 0.5 \%$. The density of the pure liquids and their binary mixtures were measured using single - capillary pycnometer. The capillary containing the graduated marks had uniform bore which can be closed by using well fitting glass cap. The marks on the capillary were calibrated by using distilled water. The measured densities were reproducible within \pm 0.0001 gram per $\mathrm{cm}^{3}$. The temperature of the test liquids and their mixtures were maintained at $303 \pm 0.05 \mathrm{~K}$ in an electronically controlled thermostatic water bottle. The sample chosen for the study is $\mathrm{NaCl}$ and $\mathrm{KCl}$. The required solutions of different concentration were prepared with distilled water.

\section{COMPUTATION:}

In the present paper we have computed Ultrasonic Velocity, Rao's Constant, Hydration Number, Relative association, Wada Constant and Free length

Ultrasonic Velocity $C^{2}=[\rho \beta s]^{-1}$

Rao's Constant $\mathrm{C}^{1 / 3} \mathrm{~V}=\mathrm{R}$

Hydration Number $\mathrm{h}=\mathrm{n}_{\mathrm{w}} / \mathrm{n}_{\mathrm{i}}\left(1-\left(\beta_{\text {soln }} / \beta_{\text {solv }}\right)\right)$

Relative association $\mathrm{RA}=\rho / \rho_{0}(\mathrm{C} 0 / \mathrm{C}) 1^{1 / 3}$

Wada Constant $B=M\left(\beta_{\mathrm{s}}\right)^{-1 / 7} / \rho$

Free length $L_{\mathrm{f}}=\mathrm{K} \beta_{\mathrm{s}}^{1 / 2}$ 
Where $\mathrm{M}$ is the molecular weight, $\beta_{\text {soln and }} \beta_{\text {solv }}$ are the compressibility's of solution and solvent, $\rho$ being the density of the medium, $\beta_{\mathrm{s}}$ isentropic compressibility, $\mathrm{V}$ molar volume, $\mathrm{n}_{\mathrm{w}} \mathrm{n}$ mole of water, $\mathrm{n}_{\mathrm{i}} \mathrm{n}$ mole of ion, $\rho_{0}$ and $\mathrm{C}_{0}$ are the density and ultrasonic velocity of water at $0^{\circ} \mathrm{C}, \mathrm{K}$ temperature dependent constant value being $1.99539 \times 10^{-6}$ in M.K.S system.

Table 1: ultrasonic velocity and related parameters for aqueous solutions of nacl:

\begin{tabular}{|c|c|c|c|c|c|c|c|c|}
\hline $\mathrm{X}$ moles & $\mathrm{C} \mathrm{ms}^{-1}$ & $\begin{array}{l}\rho \mathrm{Kgm}^{-3} \\
\mathrm{x10}^{3}\end{array}$ & $\begin{array}{l}\beta_{\mathrm{s}} \mathrm{m}^{2} \mathrm{~N}^{-1} \\
\mathbf{x} 10^{-10}\end{array}$ & h & $R \times 10^{-3}$ & B $\times 10^{-3}$ & $\begin{array}{l}L_{F} \mathbf{m}_{\mathbf{x}} \\
\mathbf{x} \mathbf{1 0}^{-10}\end{array}$ & $\mathbf{R A}$ \\
\hline 0.1 & 1514 & 1.0022 & 4.3535 & 13.265 & 2.705 & 5.122 & 0.4163 & 0.9766 \\
\hline 0.2 & 1521 & 1.0043 & 4.2998 & 9.975 & 2.717 & 5.146 & 0.4137 & 0.9771 \\
\hline 0.3 & 1529 & 1.0064 & 4.2501 & 8.713 & 2.727 & 5.164 & 0.4114 & 0.9774 \\
\hline 0.4 & 1535 & 1.0093 & 4.2046 & 7.951 & 2.734 & 5.178 & 0.4092 & 0.9790 \\
\hline 0.5 & 1538 & 1.0111 & 4.1796 & 6.983 & 2.74 & 5.192 & 0.4079 & 0.9804 \\
\hline 0.6 & 1549 & 1.0131 & 4.1136 & 7.189 & 2.754 & 5.217 & 0.4047 & 0.9797 \\
\hline
\end{tabular}

$\mathrm{X}-$ Concentration of electrolyte

C - Ultrasonic velocity

$\rho$ - Density of the solution

$\beta_{\mathrm{s}}{ }^{-}$Adiabatic compressibility

$\mathrm{h}$ - Hydration number

$$
\begin{aligned}
& \text { R - Rao's number } \\
& \text { B - Wada's constant }
\end{aligned}
$$

$\mathrm{L}_{\mathrm{F}}$ - Free length

RA - Relative association

\begin{tabular}{|c|c|c|c|c|c|c|c|c|}
\hline $\mathrm{X}$ moles & $\mathrm{C} \mathrm{ms}^{-1}$ & $\begin{array}{l}\rho \mathrm{Kgm}^{-3} \\
\times 10^{3}\end{array}$ & $\begin{array}{l}\beta_{\mathrm{s}} \mathrm{m}^{2} \mathrm{~N}^{-1} \\
\mathbf{x} 10^{-10}\end{array}$ & h & $\mathrm{R} \times 10^{-3}$ & B $\times 10^{-3}$ & $\begin{array}{l}L_{F} m \\
x 10^{-10}\end{array}$ & RA \\
\hline 0.1 & 1509 & 1.0023 & 4.3816 & 7.652 & 2.241 & 4.245 & 0.4177 & 0.9777 \\
\hline 0.2 & 1517 & 1.0050 & 4.3236 & 6.657 & 2.254 & 4.270 & 0.4149 & 0.9786 \\
\hline 0.3 & 1524 & 1.0079 & 4.2715 & 6.134 & 2.285 & 4.286 & 0.4124 & 0.9798 \\
\hline 0.4 & 1526 & 1.0107 & 4.2484 & 5.163 & 2.286 & 4.333 & 0.4113 & 0.9823 \\
\hline 0.5 & 1532 & 1.0122 & 4.2090 & 4.901 & 2.293 & 4.345 & 0.4094 & 0.9825 \\
\hline 0.6 & 1541 & 1.0154 & 4.147 & 5.093 & 2.305 & 4.370 & 0.4065 & 0.9836 \\
\hline
\end{tabular}

Table 2: ultrasonic velocity and related parameters for aqueous solutions of $\mathrm{kcl}$ :

$\mathrm{X}$ - Concentration of electrolyte

C - Ultrasonic velocity

$\rho-$ Density of the solution

$\beta_{\mathrm{s}}$ - Adiabatic compressibility

$\mathrm{h}$ - Hydration number

\author{
$\mathrm{R}$ - Rao's number \\ B - Wada's constant
}

$\mathrm{L}_{\mathrm{F}}$ - Free length

RA - Relative association 
Fig:1 plot of velocity(C) Vs concentration of alkali halide in water
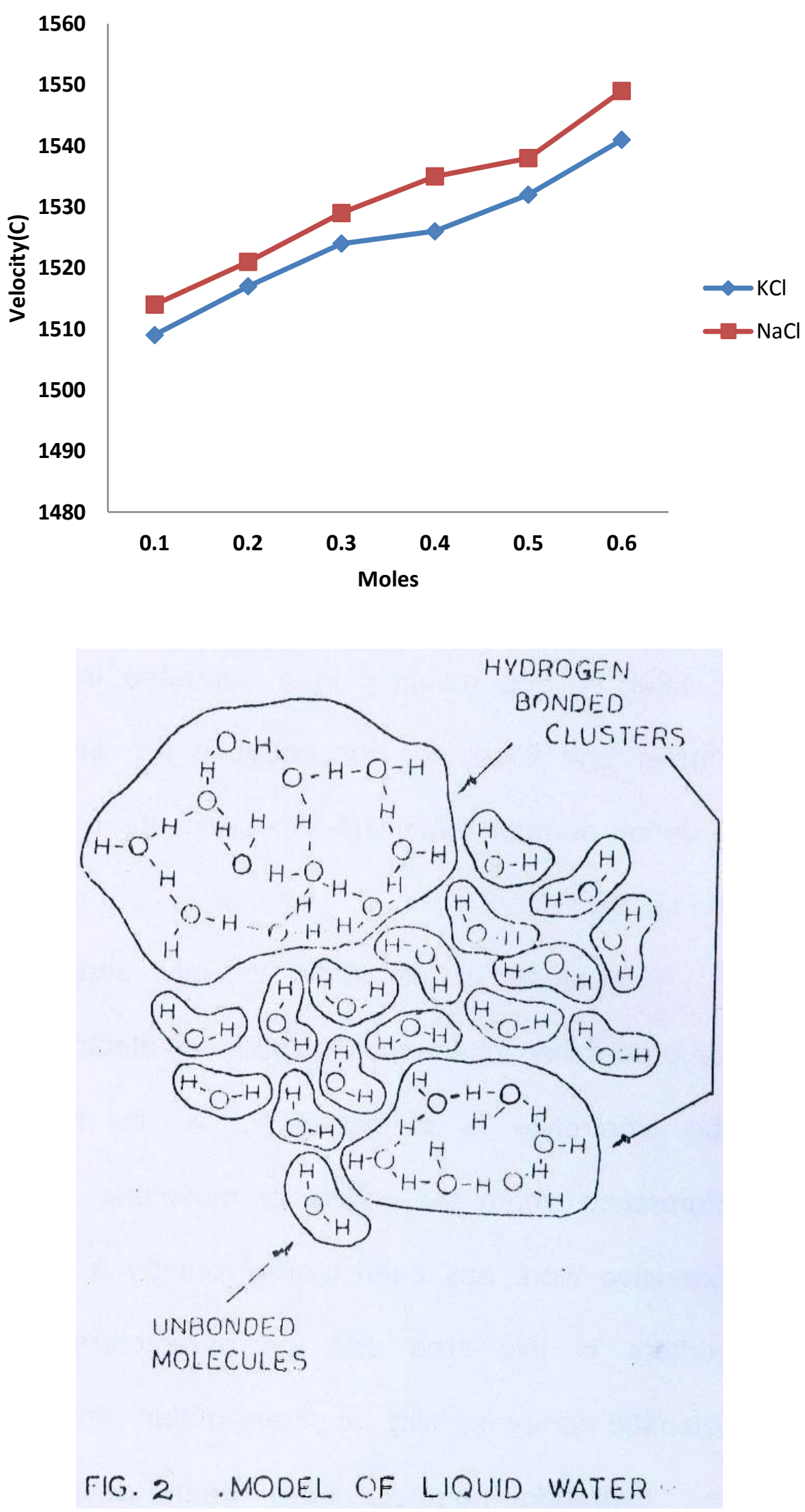


\section{Fig:3 Plot of Density Vs concentration of alkali halide in water}

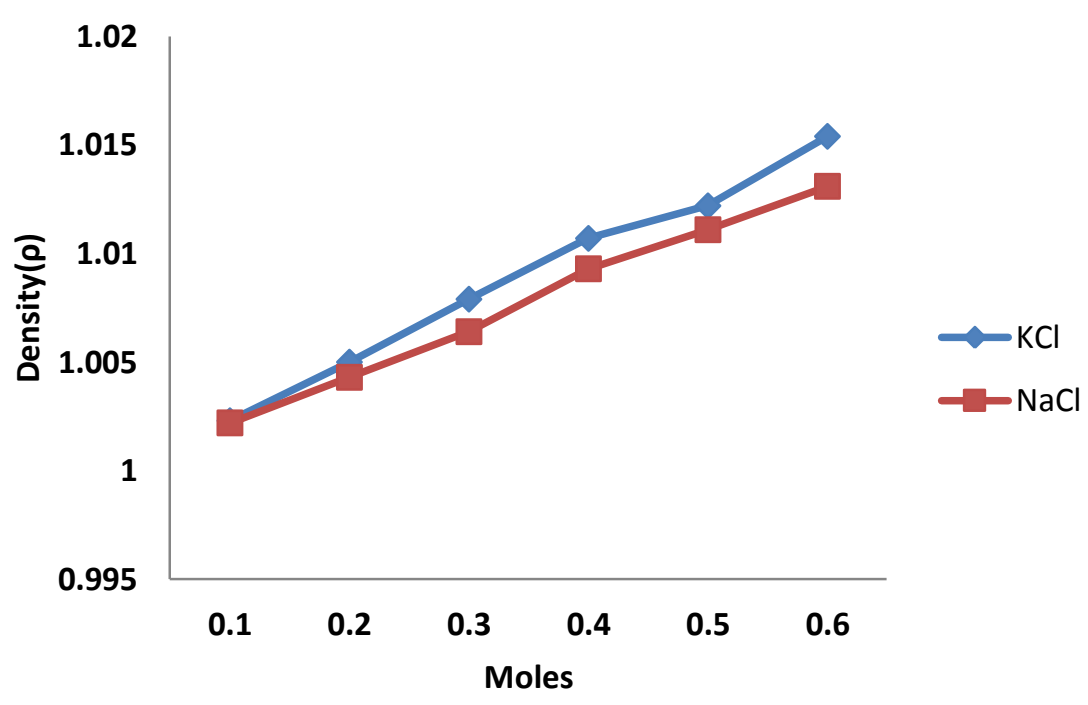

Fig:4 Plot of Adiabatic compressibility( $\beta$ ) Vs concentration of alkali halide in water

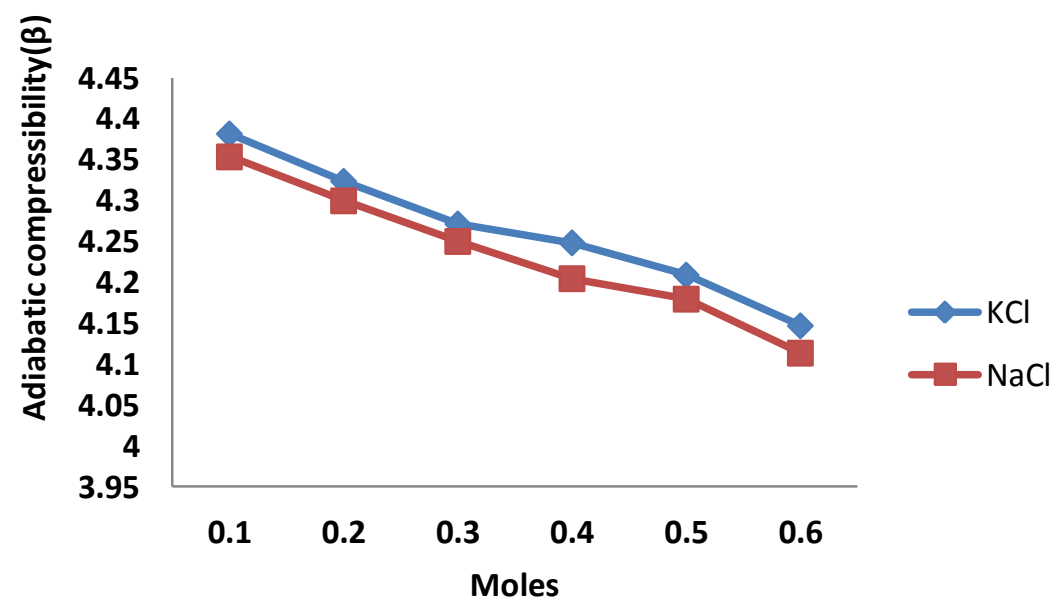

\section{RESULTS}

The results of studies are summarized as follows from table $1 \& 2$. It is observed that the ultrasonic velocity in the aqueous solutions of $\mathrm{NaCl}$ and $\mathrm{KCl}$ increases with the increase in concentration of the alkali halides $(0.1$ to $0.6 \mathrm{M})$ and are found to be higher than the ultrasonic velocity in water. Ultrasonic velocities in 0.1 to $0.6 \mathrm{M}$ aqueous solutions of $\mathrm{NaCl}$ are found to be higher than the ultrasonic velocities of 0.1 to $0.6 \mathrm{M}$ aqueous solution of $\mathrm{KCl}$. The densities of the aqueous solution of $\mathrm{NaCl}$ and $\mathrm{KCl}$ are found to increase with the increase in concentration of alkali halides. The densities of aqueous solutions of $\mathrm{KCl}$ are found to be larger than the densities of aqueous solutions of $\mathrm{NaCl}$ in the concentrations range studied.The adiabatic compressibility of all $\mathrm{NaCl}$ and $\mathrm{KCl}$ aqueous solutions decrease with the increase in concentration of alkali halide. The adiabatic compressibility of $\mathrm{NaCl}$ solutions is found to be smaller in comparison with $\mathrm{KCl}$ solutions. The hydration numbers of aqueous solutions of $\mathrm{NaCl}$ are in general found to be larger in comparison with the hydration number of aqueous solutions of $\mathrm{KCl}$. The hydration number of aqueous solutions of $\mathrm{NaCl}$ and $\mathrm{KCl}$ are found to decrease with increase in concentration of alkali halide. However for the concentration range $0.5 \mathrm{M}$ and $0.6 \mathrm{M}$ there is no appreciable change in the hydration number of $\mathrm{NaCl}$ and $\mathrm{KCl}$ solutions. The Rao's number and Wada's constant are found to increase with increase of concentration of both $\mathrm{NaCl}$ and $\mathrm{KCl}$ in aqueous solutions. Both these computed parameters are found to be higher for aqueous $\mathrm{NaCl}$ system in comparison to aqueous $\mathrm{KCl}$ solution, the inter-molecular free length is found to decrease in both the system studied. The relative association is found to increase with increase in concentration in both $\mathrm{NaCl}$ and $\mathrm{KCl}$ aqueous solutions. Also the density of $\mathrm{NaCl}$ and $\mathrm{KCl}$ increases with increase of concentration. 


\section{DISCUSSION}

In the present studies it is observed that the ultrasonic velocities are higher in $\mathrm{NaCl}$ and $\mathrm{KCl}$ solutions than in water. The ultrasonic velocity increases as the concentration of $\mathrm{NaCl}$ and $\mathrm{KCl}$ is increased (Fig1 and tab 1\&2). However the ultrasonic velocity is higher in $\mathrm{NaCl}$ solutions than in $\mathrm{KCl}$ solutions for the same molar concentration. The increase in the ultrasonic velocity in any solution generally indicates a greater association of the molecules in them. The greater association may be due to phenomena like hydrogen bonding or ionic hydration of the solutes. In the present studies the increased cohesion between the molecules in the solution appears to be due to the ionic hydration. $\mathrm{NaCl}$ and $\mathrm{KCl}$ are strong electrolytes which dissolve in water to form $\mathrm{Na}^{+}$and $\mathrm{K}^{+}$and $\mathrm{Cl}^{-}$ions. The tendency of an atom or an ion in a system to attract electrons to itself is called electro-negativity. Chlorine, Fluorine is highly electronegative. The tendency of an element to give away electrons is called electropositive nature. Sodium and potassium are highly electro positive.

Water molecules are attached to the ions strongly by electrostatic forces which introduces a greater cohesion in the solution. The ionic radii of sodium, potassium and chlorine are $0.95 \AA$ Á, $1.33 \AA$ Á and 1.81 ̊́ (Rao CNR 1967). From the literature it can be seen that the relativity small ions induce higher order in water structure (Kavanu 1964). Higher order in the solution means a lower compressibility and a higher ultrasonic velocity. In the present studies, the ultrasonic velocities in aqueous solutions containing $\mathrm{Na}^{+}$ with ionic radius of $0.95 \AA$ are found to be larger than in solutions containing $\mathrm{K}^{+}$with ionic radius $1.33 \AA$. The lower values of compressibility aqueous solutions of $\mathrm{NaCl}$ in comparison to $\mathrm{KCl}$ solution (tab1.2 and fig 4) also suggest that there is higher order in the aqueous solutions of $\mathrm{NaCl}$ than $\mathrm{KCl}$ solution. The $\mathrm{NaCl}$ and $\mathrm{KCl}$ which disassociates into $\mathrm{Na}^{+}$and $\mathrm{K}^{+}$and $\mathrm{Cl}^{-}$in the solutions are hydrated by water molecules. The hydrated water molecules are held strongly by electrostatic forces. These are highly incompressible and the compressibility of the solutions is due to the remaining solvents.

The hydration numbers are defined as the number of water molecules rigidly bound to the ions. They are also known as primary hydration numbers. Water molecules are bound to an ion of $\mathrm{NaCl}$ and $\mathrm{KCl}$ more firmly than water molecules which are bounded to each other in pure water. If such water molecules are held at the surface of the ion more strongly than the water molecules in pure water, the net effect is known as positive hydration and this enhances the structure of the solution as compared to the bulk solvent.

The structure of water near an ion can be described by referring to three regions.

1. The primary or structure enhanced region next to the ion where the water molecules are immobilized and oriented by the ionic fields and water molecules move as and where the ion moves.

2. A secondary or structure broken region in which the normal bulk structure of water is broken down to varying degree and water is partly oriented.
3. At sufficient distance from the ion, the water structure is unaffected by ion and displays the tetrahedral bonded network characteristic of bulk water.

The compressibility data of the current studies indicates the primary hydration number. From tab $1 \& 2$ it can be seen that $0.1 \mathrm{M} \mathrm{NaCl}$ solution possess a larger hydration number in comparison to $0.1 \mathrm{M} \mathrm{KCl}$ solution and as concentration of $\mathrm{NaCl}$ and $\mathrm{KCl}$ increases the hydration number decreases and remaining almost the same for concentration of 0.5 and 0.6 $\mathrm{NaCl}$ and $\mathrm{KCl}$ solutions (fig5). This can be explained with the help of flickering cluster model proposed by Frank and Wen (1957). This model postulates that formation of hydrogen bonds in liquid water is predominantly a cooperative phenomenon. The existence of pair of hydrogen bonded atoms promotes the tendency of each atom hydrogen bond to another neighbor. This results in the formation of short lived flickering clusters of varying extent, consisting of highly hydrogen bonded molecules. These clusters are mixed with non hydrogen bonded molecules (water monomer) Fig 2. The strong the electrolytes like alkali halides break up into ions due to large dielectric constant water. The ions in turn attract the water dipoles and polarize and orient them by strong electrostatic forces. The water molecules surrounding the immediate vicinity are termed as primary hydration. They also induce additional order beyond the first water layer which is known as secondary hydration or long range hydration (Bockaris 1970). This is structure broken region. The alkali halides $\mathrm{NaCl}, \mathrm{KCl}$ dissolved in the aqueous solutions are likely to be hydrated by water monomers. Increasing the concentration of $\mathrm{NaCl}$ and $\mathrm{KCl}$ results in the additional ions in the solutions and may probably take up water molecules from the secondary hydration shell which is not bound strong to ion-water complex. Further increase in concentration of $\mathrm{NaCl}$ and $\mathrm{KCl}$ may be insensitive to attract any more molecules. Thus the hydration numbers computed are found to be large at $0.1 \mathrm{M}$ and increase in concentration of alkali halides resulting in a decrease in hydration number and finally for concentration 0.5 and 0.6 the hydration number remains almost constant. (tab1, 2 \& Fig5) The study of ultrasonic velocity and adiabatic compressibility in aqueous solution of electrolytes and non electrolyte is of paramount $\mathrm{X}$, as it provides information about the nature of molecular interaction. Extensive work has been carried out by a number of workers in this area and the parameters such as adiabatic compressibility, apparent molar compressibility and hydration numbers have been determined in aqueous solutions of different electrolytes. In aqueous solutions of electrolytes such as $\mathrm{NaCl}$ and $\mathrm{KCl}$ the sound velocities are more than that of water in aqueous electrolyte solutions. But its velocity decreases for the same combinations as we move from $\mathrm{Na}$ and $\mathrm{K}$. This is because $\mathrm{Na}+$ ion is lighter than $\mathrm{K}+$ ion. Heavy ions have smaller velocity of Brownian motion.

The hydration number of aqueous solutions of $\mathrm{NaCl}$ is larger when compared to $\mathrm{KCl}$ solutions. This may be due to the fact that $\mathrm{Na}+$ which is relatively small ion when compared 
to $\mathrm{K}+$ with a large ionic radius induces a higher order in the structure of water than $\mathrm{K}+$ ions. An observed increase in Rao's constant(R) Wada's constant (B) and relative association (RA) and a decrease in free length (tab1.2) in general support the discussion furnished above. The large hydration number of sodium ion at $0.1 \mathrm{M}$ concentration of $\mathrm{NaCl}$ solution may probably be a suitable reason for its application as an intravenous transfusion fluid. It is observed that only at this concentration the hydration is a maximum which means the ion carries more number of water molecules along with it. When given as an intravenous transfusion fluid, the hydrated ion may compensate for the losses of water under dehydration conditions, thus bringing in a balance measurement of electrolytes in human physiology. The density of $\mathrm{NaCl}$ and $\mathrm{KCl}$ increases with increase of concentration shows that both $\mathrm{NaCl}$ and $\mathrm{KCl}$ possess higher solubility with water which in turn increases the density of solution.

\section{CONCLUSION}

Following facts were observed from experimental findings:

1. Various acoustical parameters have suggested the existence of powerful molecular interactions in the solutions.

2. The $\mathrm{NaCl}$ and $\mathrm{KCl}$ have structure forming tendency in the solvent system.

3. Both Solute solute interaction and solute solvent interactions are possible in the system.

\section{REFERENCES}

[1] Kavanu. J. (1964) "Water and solute water interactions" Ho/Den - day Inc Amsteredam.

[2] Wada. Y. (1946) J.Phys.Soc.Japan 4, 280

[3] Narasimhan. A.V, Ind.Jol.Pure\&App.Physics, 8, 413 (1970)

[4] Nikam P.S Mahale TR \& Hasan M.Acustica, Acia Acustica 84 (1998) 579

[5] A.N.Kannppan, K.Ramalingam \& R.Palani, Ind.jol. Pure \& app.Physics, 29,43(1982).

[6] O.Nomoto J.Chem.Soc.Jpn, 11.1146 (1956)

[7] Eyring H \& Kincaid J.F.J chem. . Phys, 6 (1938) 620.

[8] J.Palak, S.Murakami, V.T. Lam, H.D.Pflug and G.C Benson, Can.J.Chem 48 (1970)

[9] R.R Yadava, S.S Yadava, J.chem, Eng.Data 32 (1987) 54.

[10] S.Sing, R.Sing, N.Parasad and S.Prakash, Ind.Jol.Pur \& App Physics, 15,629 (1977).

[11] M.G.S.Rao and B.R.Rao Nature, 181, 164 (1961). 